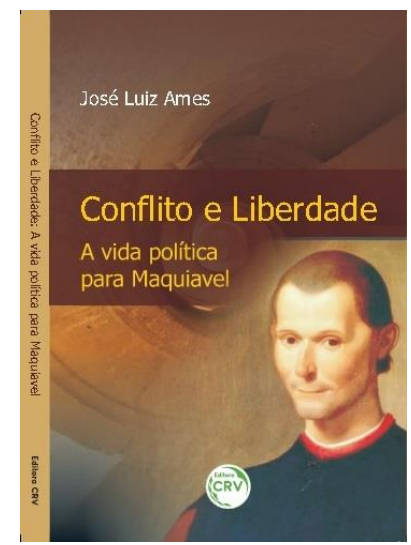

RESENHA: AMES, José Luiz. Conflito e Liberdade: a vida política para Maquiavel. Curitiba: CRV, 2017.

\title{
Conflito e Liberdade: a vida política para Maquiavel
}

\author{
FABIANA DE JESUS BENETTI ${ }^{12}$
}

O Livro Conflito e Liberdade: a vida política para Maquiavel, é o mais novo trabalho publicado por José Luiz Ames (2017), professor associado do curso de Filosofia, pela Universidade Estadual do Oeste do Paraná. Ames, que nos últimos anos tem contribuído expressivamente para a pesquisa e divulgação do pensamento de Maquiavel no Brasil, apresenta-nos um trabalho de grande fôlego sobre o tema do conflito político e a sua relação com o conceito de liberdade. Este tema tem aparecido nas pesquisas de muitos estudiosos do pensamento de Maquiavel no Brasil, em especial nos estudos mais recentes, no entanto podemos dizer que o livro de Ames é pioneiro em trazer o tema como o núcleo de seu trabalho.

Construído a partir da divisão em cinco capítulos, o texto de Ames se estrutura tematicamente da seguinte forma: o primeiro capítulo traz uma investigação acerca dos diversos sentidos que têm o conceito de liberdade no pensamento de Maquiavel; os três capítulos seguintes têm como temática a investigação acerca da relação entre conflito e liberdade nas obras O Príncipe, Discursos sobre a primeira década de Tito Lívio e História de Florença, respectivamente; o quinto e último livro, traz o tema do conflito político do modo como vem senso inserido nos debates políticos contemporâneos. É verdade que Ames traz como tema nuclear a relação entre conflito e liberdade, mas ao final da leitura pode-se confirmar que, assim como é expresso no título, o autor perpassa a temática inicial, no sentido de oferecer

\footnotetext{
${ }^{1}$ Doutoranda pelo Programa de Pós-Graduação em Filosofia, na linha de Ética e Filosofia Política, da Universidade Estadual do Oeste do Paraná. E-mail: benettifabiana@hotmail.com.

${ }^{2} \mathrm{O}$ presente trabalho foi realizado com apoio da Coordenação de Aperfeiçoamento de Pessoal de Nível Superior - Brasil (CAPES) - Código de Financiamento ooı.
} 
ao leitor um panorama sobre o significado que tem a vida política no pensamento de Maquiavel. E o faz com a clareza que é própria das exposições de Ames, tanto como pesquisador quanto como professor.

Já na introdução, Ames evidencia a importância que tem a temática do conflito político não só internamente à obra de Maquiavel, mas também pelas consequências exteriores a ela. Ames, seguindo uma perspectiva de Stefano Visentin, dirá que assim como ocorre com o conceito de soberania de Hobbes, também o conceito de conflito político de Maquiavel constituiu um marco importante para a inauguração da modernidade política. Em sua perspectiva, "o marco inicial da modernidade política, em uma palavra, está no reconhecimento de que no princípio de qualquer ordenamento político está o conflito" (AMES, 2017, p. 20). É partindo desta tese que Ames apresenta Maquiavel como o pensador que, de modo inicial, reflete sobre a vida pública a partir do seu caráter conflitivo; como o primeiro autor que teria feito "a reflexão em torno do conflito como princípio vital tanto dos ordenamentos políticos enquanto tais, quanto das instituições das quais estes são compostos" (AMES, 2017, p. 20). E as características principais do conflito são indicadas por Ames quando ele explica a afirmação de Maquiavel de que há uma cisão radical em todas as cidades entre os desejos antagônicos de grandes e povo: grandes desejando dominar e povo desejando não ser dominado. Se para uma longa tradição política a ideia de conflito foi tratada como algo destruidor da vida política, Ames vai mostrando como em Maquiavel, ao contrário, o conflito passa a ter um papel edificante de ordenamentos políticos. Isto porque, no pensamento do florentino, conflito não significa o mesmo que violência pura, não se trata da existência de uma guerra civil. É nesta visão positiva acerca dos conflitos, que Maquiavel rompe com a tradição aristotélica e ciceroniana e, também, promove uma diferença marcante com aquilo que mais tarde será apresentado pela tradição do pensamento contratualista moderno: o conflito não é um problema a ser resolvido a partir de uma política que promova o seu aniquilamento, ao contrário disto, a extirpação do conflito pode significar a extirpação da própria vida política. Estas informações que Ames apresenta vão fazendo o leitor perceber que a novidade de Maquiavel não está na descoberta da existência dos conflitos, mas sim na importância que ele dá a eles para a vivacidade política.

Encerrando a introdução com uma exposição geral acerca do que o leitor poderá encontrar em cada capítulo da obra, Ames abre o primeiro capítulo de seu livro trazendo uma apresentação dos diversos significados que tem o termo libertà no pensamento de Maquiavel. Para Ames, compreender os usos gerais do termo permitirá que se obtenha uma maior clareza com relação ao significado do conceito específico que se pretende trabalhar, que é o de liberdade política. Nesta perspectiva, Ames vai demonstrando que há sim momentos em que Maquiavel apresenta o termo em conformidade com sentidos tradicionais, seja, por exemplo, 
quando ele aparece como sinônimo de liberdade individual (no sentido aristotélico do termo), seja quando ele aparece como sinônimo de liberdade de escolha, no uso do termo "livre arbítrio". No entanto, embora tais significados possam aparecer nos textos de Maquiavel, o que é de maior importância é a acepção política do termo liberdade. O que Ames vai demonstrando ao longo do capítulo é que, no pensamento de Maquiavel, o conceito central de liberdade não está atrelado a escolhas subjetivas ou abstratas, mas sim a escolhas que situam o homem no curso da história. Os próprios termos de liberdade e livre arbítrio não devem tomar o sentido de essências abstratas no pensamento do florentino, visto que são utilizados para indicar as escolhas que colocam os homens como responsáveis pelos cursos que a história toma. Como o próprio Ames enfatiza, "é preciso ressaltar que tanto liberdade quanto livre arbítrio, como qualidades do homem, são sempre compreendidas em um contexto sócio-histórico bem determinado e não em uma perspectiva individual e subjetiva" (AMES, 2017, p. 37). Para Ames, este é conceito nuclear de liberdade para Maquiavel: liberdade como experiência política, que se efetiva historicamente na relação dos homens com outros homens.

Nos próximos três capítulos do livro, Ames passa a investigar o conceito de liberdade e conflito em três obras de Maquiavel: O Príncipe, Discursos e História de Florença. Mas, embora tenha delineado esta temática específica para os três capítulos, o que Ames reserva ao leitor é uma abordagem que se amplia e se direciona de modo fecundo a uma diversidade de assuntos que compõem as estruturas temáticas em torno do conflito político. E para enriquecimento do texto, Ames vai tecendo um diálogo com importantes pensadores de Maquiavel na atualidade, num movimento que nos permite acompanhar não só o que pensa Ames, mas também o que pensam os seus interlocutores.

No capítulo dedicado ao Príncipe, o problema central, apresentado por Ames, remete à questão sobre a dinâmica do conflito em um principado. Tendo em vista que nas repúblicas o conflito pode ser regulado pelas estruturas institucionais, que tem como função regular e dar vazão a eles, a questão que Ames questiona é:

E sob um principado, valeria também nele a ideia segundo a qual o conflito não pode ser neutralizado, mas apenas "canalizado" pelo príncipe? A dúvida é reforçada pelo fato de em semelhante forma política, à primeira vista, a segurança e a estabilidade dependerem exclusivamente da virtù do príncipe (AMES, 2017, p. 43).

A hipótese que Ames toma como ponto de partida para a reflexão, assenta-se numa leitura comum do texto de Maquiavel, segundo a qual há dois modos a partir dos quais o príncipe pode controlar o conflito: o primeiro pelo uso da força e o segundo pela distribuição de favores. $\mathrm{O}$ uso de tais vias sugere, segundo Ames, a inviabilidade de que em um principado se possa usar de saídas institucionais como ocorre nas repúblicas. Tendo isto em vista, Ames expressa sua intenção de analisar a 
temática do conflito em $O$ Príncipe com o intuito de verificar a pertinência ou não desta posição, ou seja, buscará responder se há, de fato, a impossibilidade do uso de vias institucionais em um principado, ou, se, ao contrário disso, esta saída pode lhe ser aplicada. O que Ames argumentará na sequência do capítulo é que a manutenção de um principado não pode depender de uma exclusividade do príncipe com relação ao poder político, ao contrário disto, a sua manutenção depende de como o poder é dividido entre as potências da cena pública. Nesta perspectiva, Ames faz ver os rompimentos de Maquiavel com teorias de regimes principescos que pensam na concentração do poder, unicamente, na figura do governante. Conforme o autor vai indicando, em Maquiavel, mesmo em um principado, há uma necessidade de partilha do poder, o que significa que a solidez deste tipo de governo está estritamente vinculada ao que Ames denomina de "jogo das alianças”. Este jogo de alianças acontece entre o príncipe e as forças que na cidade estão em conflito, escolha que se dará na consideração de qual aliança será mais benéfica ao governo. Em termos gerais, Ames demonstra que a solução mais apropriada é a aliança com o povo, o que não significa que o príncipe deve excluir ou ignorar os grandes em seu governo.

No terceiro capítulo, Ames inicia a análise da dinâmica do conflito nas repúblicas, tendo como referencial os Discursos sobre a primeira década de Tito Lívio. Este nos parece o capítulo mais central à questão da relação entre conflito e liberdade, tendo em vista a maior fluidez política que é própria desta espécie de governo. Tomando como ponto de partida a divisão social que culmina nos conflitos internos às cidades, Ames diz que a divisão social pode ser pensada a partir de duas lógicas opostas: a lógica da homogeneidade e a lógica da heterogeneidade. A lógica da homogeneidade deriva de uma disputa entre rivais que objetivam os mesmos bens; já a lógica da heterogeneidade acorre na tensão dos objetos opostos, ou seja, acontece entre os atores políticos cujos objetos de desejos são coisas contrárias. Enquanto na lógica da homogeneidade ocorre uma relação de forças, a lógica da heterogeneidade circunscreve-se na lógica da oposição. Enquanto na primeira revela-se um embate que fraciona a sociedade política, pois o jogo de forças se dá entre facções, no segundo caso revela-se o conflito que pode ser salutar à vida social, visto que a tensão entre os que desejam dominar e os que desejam não ser dominados, pode ter como resultado a liberdade política. Ora, esta é uma informação que intriga o leitor atento, pois desperta a curiosidade em entender o porquê desta dinâmica. Ou seja, de entender como uma tensão entre desejos que são de natureza assimétrica, pode ter como resultado a liberdade do todo político. Após um percurso no qual o autor vai se debruçando sobre conceitos importantes no pensamento de Maquiavel (como os de lei, de necessidade, de conflito), Ames demonstra como a dinâmica do conflito é produtora de bens públicos. Como o autor explica, 
a acumulação de meios de opressão para serem exercidos sobre o povo por parte dos grandes encontra no povo uma busca correspondente (mas não necessariamente equivalente) de meios de resistência no sentido de conter a opressão. O resultado deste confronto/ cooperação é a produção de leggi et ordini capazes de limitar a desmesura dos grandes e viabilizar um vivere libero político (AMES, 2017, p. 83).

Com esta afirmação, Ames chama a atenção para o movimento de resistência do desejo do povo ao desejo dos grandes, pois é este enfrentamento que pode culminar na produção de boas leggi et ordini, capaz de promover a vida política livre. Tão importante como a demonstração deste caminho é a explicação de Ames que permite ao leitor compreender em que consiste este vivere libero. Segundo ele, o vivere libero não se trata de um ordenamento político no qual não exista dominação, mas sim de uma situação de contenção do desejo dominante dos grandes. Deste modo, a vida livre ocorre quando se tem na cidade um grupo de resistência aos desejos dominantes e opressores, na medida em que esta resistência seja capaz de produzir os meios institucionais de contenção da dominação que pretendem os grandes. Sem esta resistência que dá vida ao conflito político, a cidade seria somente o espaço dos interesses privados. Inclusive é nesta temática das cidades que se deixam ordenar por facções, por interesses privados, que se inscreve o capítulo seguinte do texto de Ames.

No quarto capítulo do livro, Ames reflete sobre os modelos de república de Roma e Florença, a fim de demonstrar como a dinâmica do conflito teve consequências distintas em cada uma delas, em decorrência das mudanças de foco do desejo popular. Se em Roma o que prevaleceu foi a divisão e o conflito entre os humores de grandes e povo, em Florença uma outra dinâmica tomou o espaço da vida pública: a organização de seitas que tomaram conta do espaço público. A explicação desta diferença de dinâmicas nas cidades é feita por Ames quando observa que, enquanto em Roma o povo tinha como pretensão compartilhar das magistraturas com os nobres, em Florença a pretensão foi a de governar sozinho sem a partilha de poderes. Para Ames, este movimento provoca uma mudança da própria característica do desejo popular, se antes ele se inscrevia na negatividade do desejo de não ser dominado, agora ele aproxima-se da positividade do desejo de dominar.

Ames faz neste capítulo toda uma análise, em especial da Revolta dos Ciompi, para pensar as mudanças de rumo que o conflito tomou em Florença. Sua intenção é a de, por um lado, pensar a dinâmica que foi característica a esta república e, por outro lado, entrar no campo de uma discussão atual que questiona se há uma mudança de posição de Maquiavel com relação à temática do conflito. Ocorre que, para alguns autores, o modo como Maquiavel teria pensado o conflito na História de Florença, destoaria do modo como o fora pensado por ele no Príncipe e nos 
Discursos, ou seja, uma visão positiva nestas duas últimas obras referidas e uma visão negativa na História de Florença. No diálogo com alguns autores, Ames apresenta uma visão que fomenta tal ideia, como é o caso de Mauricio Suchowlansky, para o qual esta mudança, na ótica do conflito, revela um pessimismo de Maquiavel com relação ao papel político do povo. E apresenta uma visão contrária a esta, como é o caso de Sérgio Cardoso que, na linha oposta, demonstra o caráter político atrelado à Revolta dos Ciompi, o que significa uma posição de que há sim continuidade entre as obras de Maquiavel. Nesta linha das discussões, Ames se atém à tese de que a caracterização que Maquiavel faz dos conflitos na História de Florença não anula a sua perspectiva com relação a eles, ao contrário disto, segundo Ames, o problema não está no conflito nele mesmo, mas na forma que foi dada aos conflitos na república florentina.

Para finalizar, Ames traz no quinto capítulo uma apresentação das leituras contemporâneas de Maquiavel, apresentando o modo como a teoria maquiaveliana do conflito político é apresentada nas discussões que fazem liberais, republicanos e democratas. Esta apropriação de Maquiavel por correntes políticas, por vezes, tão distintas, faz com que Ames nos indique o quão vivaz é o pensamento do autor florentino ainda hoje, servindo-nos para refletir sobre estruturas e movimentos políticos que perpassaram o tempo de Maquiavel.

\section{Referências}

AMES, José Luiz. Conflito e Liberdade: a vida política para Maquiavel. Curitiba: CRV, 2017.

Submissão: 25.06.2018 / Aceite: 28.06.2018. 